\title{
Fc $\gamma$ RIIIa polymorphisms and cetuximab induced cytotoxicity in squamous cell carcinoma of the head and neck
}

\author{
Rodney J. Taylor · Siaw-Lin Chan • Aaron Wood · Caroline J. Voskens • \\ Jeffrey S. Wolf · Wei Lin · Andrei Chapoval · Dan H. Schulze · Guoliang Tian · \\ Scott E. Strome
}

Published online: 13 May 2009

(C) Springer-Verlag 2009

\section{Erratum to: Cancer Immunol Immunother}

\section{DOI 10.1007/s00262-008-0613-3}

It has been brought to author's attention that Fig. 2 contains major error. Specifically, in Fig. 2a, the 'F/V' and the 'V/V' figures are identical. The correct version is given below:

The online version of the original article can be found under doi:10.1007/s00262-008-0613-3.

R. J. Taylor $(\bowtie) \cdot$ S.-L. Chan · A. Wood · J. S. Wolf · W. Lin ·

A. Chapoval · D. H. Schulze · S. E. Strome

Department of Otorhinolaryngology/Head and Neck Surgery,

Marlene and Stewart Greenebaum Cancer Center,

University of Maryland School of Medicine,

University of Maryland, 16 South Eutaw Street,

Suite 500, Baltimore, MD 21201, USA

e-mail: rtaylor@smail.umaryland.edu

\section{J. Voskens}

Department of Pathology,

University of Maryland School of Medicine, Baltimore, MD, USA

D. H. Schulze · S. E. Strome

Department of Microbiology and Immunology,

University of Maryland School of Medicine, Baltimore, MD, USA

R. J. Taylor · J. S. Wolf · G. Tian · S. E. Strome

Program in Oncology,

University of Maryland School of Medicine, Baltimore, MD, USA 


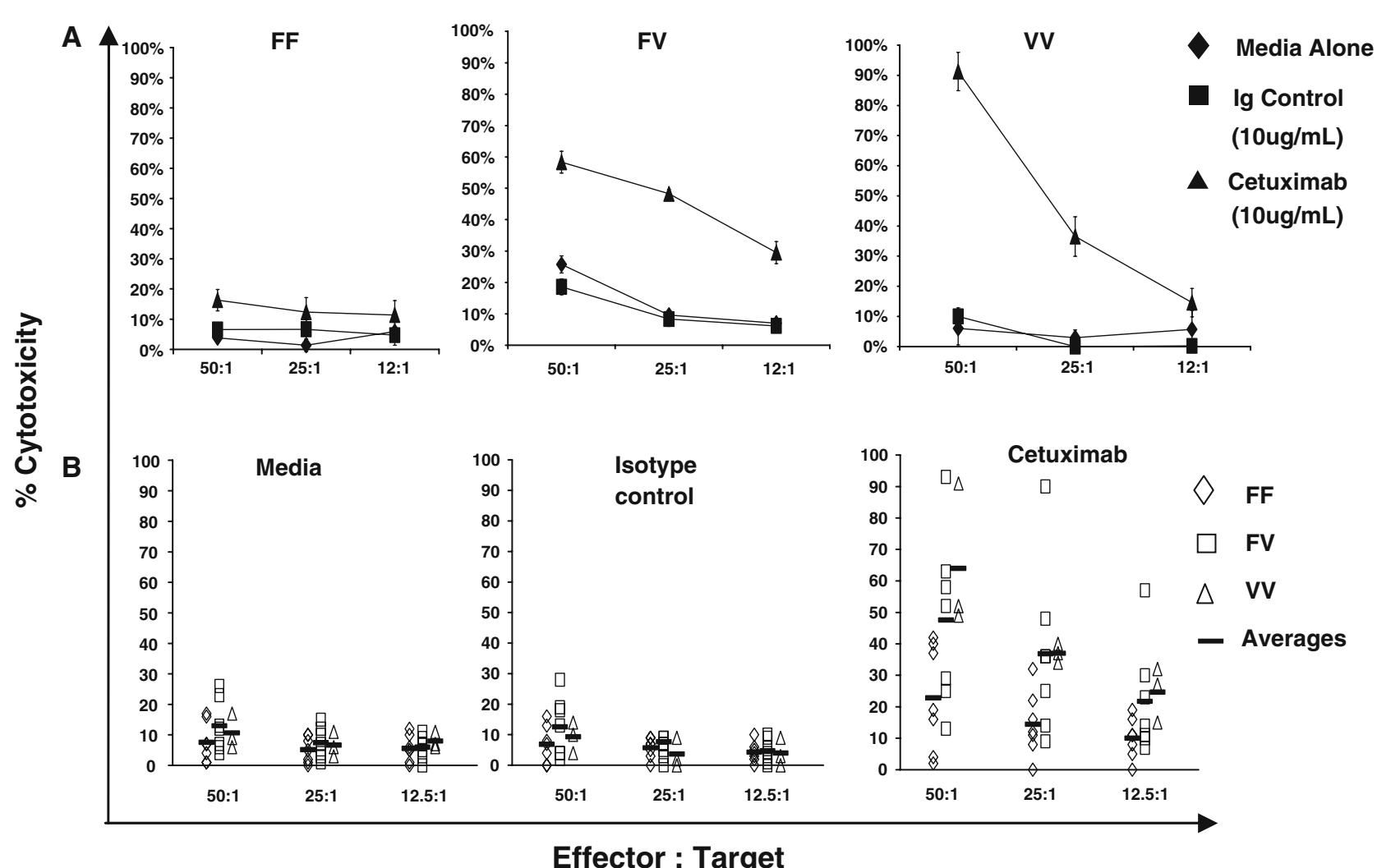

Fig. 2 NK Fc $\gamma$ RIIIa polymorphisms influencing cytotoxic activity on cetuximab-treated SCCHN TU167. a NK cells from individual donors expressing either $F / F, V / F$ or $V / V$ alleles were tested for cytotoxicity against TU167 in a standard ${ }^{51} \mathrm{Cr}$-release assay. Before addition of effector cells, TU167 target cells were pretreated with media alone (filled diamond), human $\mathrm{IgG1}$ isotype control at $10 \mu \mathrm{g} / \mathrm{ml}$ (filled square) or cetuximab $10 \mu \mathrm{g} / \mathrm{ml}$ (filled triangle). Data are representative of independent experiments performed in triplicates, with error bars indicating SEM. b NK cells from 17 donors expressing either
$F / F, V / F$ or $V / V$ alleles were tested for cytotoxicity against the TU167 SCCHN cell line using a standard ${ }^{51} \mathrm{Cr}$-release assay. Before addition of effector cells TU167 targets were pretreated with media alone, human IgG1 isotype control at $10 \mu \mathrm{g} / \mathrm{ml}$, or cetuximab at $10 \mu \mathrm{g} / \mathrm{ml}$. Donors with either Fc $\gamma$ RIIIa $V / V$ or Fc $\gamma$ RIIIa $V / F$ demonstrated significantly higher \% cytotoxicity compared to Fc $\gamma$ RIIIa $F / F$, when incubated with $10 \mu \mathrm{g} / \mathrm{mL}$ cetuximab $(P=0.04$ and 0.004 , respectively). Shown is the mean of $n=7,7$ and 3 for FF, VF and VV, respectively, with error bars representing SEM 